\title{
Lipase immobilization through the combination of bio-imprinting and cross-linked protein-coated microcrystal technology for biodiesel production
}

Jing Gao ${ }^{a, b}$, Luyan Yin ${ }^{a}$, Kai Feng ${ }^{a, b}$, Liya Zhou ${ }^{a, b}$, Li Ma $^{a, b}$, Ying He ${ }^{a, b}$, Lihui Wang ${ }^{a}$, Yanjun Jiang $^{a, b *}$

a School of Chemical Engineering and Technology, Hebei University of Technology, 8 Guangrong Road, Hongqiao District, Tianjin 300130, PR China

b Hebei Provincial Key Lab of Green Chemical Technology and High Efficient Energy Saving, Hebei University of Technology, 8 Guangrong Road, Hongqiao District, Tianjin 300130, PR China

*Corresponding Author: E-mail: yanjunjiang@hebut.edu.cn; Tel: 86-22-60204945 


\section{Biodiesel synthesis}

The reactions were performed in screw-capped vials with a capacity of $20 \mathrm{~mL}$ containing an amount of Jatropha curcas L. oil and anhydrous ethanol with the addition of $n$-hexane as solvent. Effect of various parameters on biodiesel production including molar ratio of Jatropha curcas $L$. oil to $n$-hexane, temperature, molar ratio of ethanol to oil, the dosage of biocatalysts were studied. The amount of esters was determined by gas chromatography (GC). 


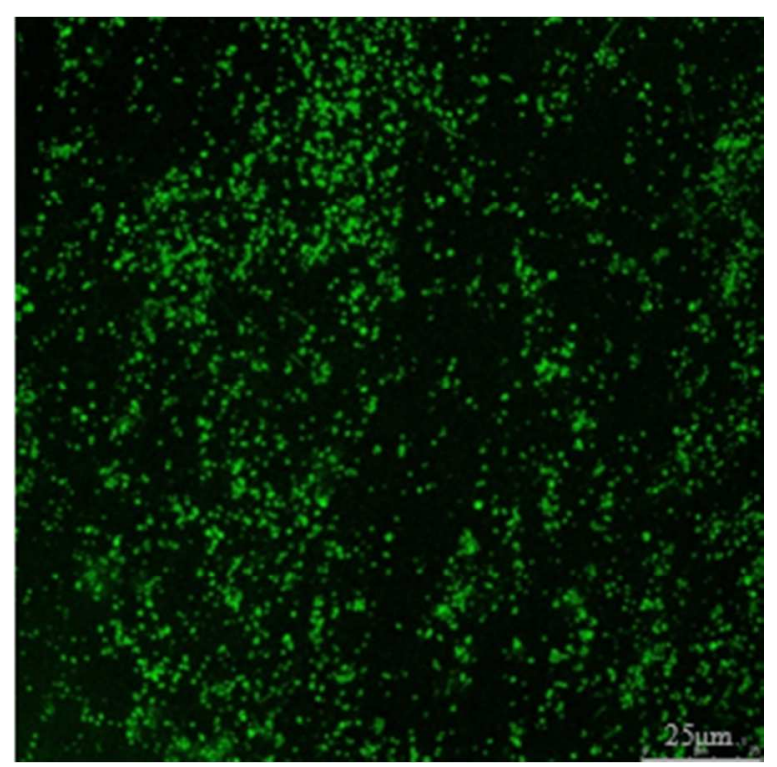

Figure S1 Confocal image of IM-CLPCMC 


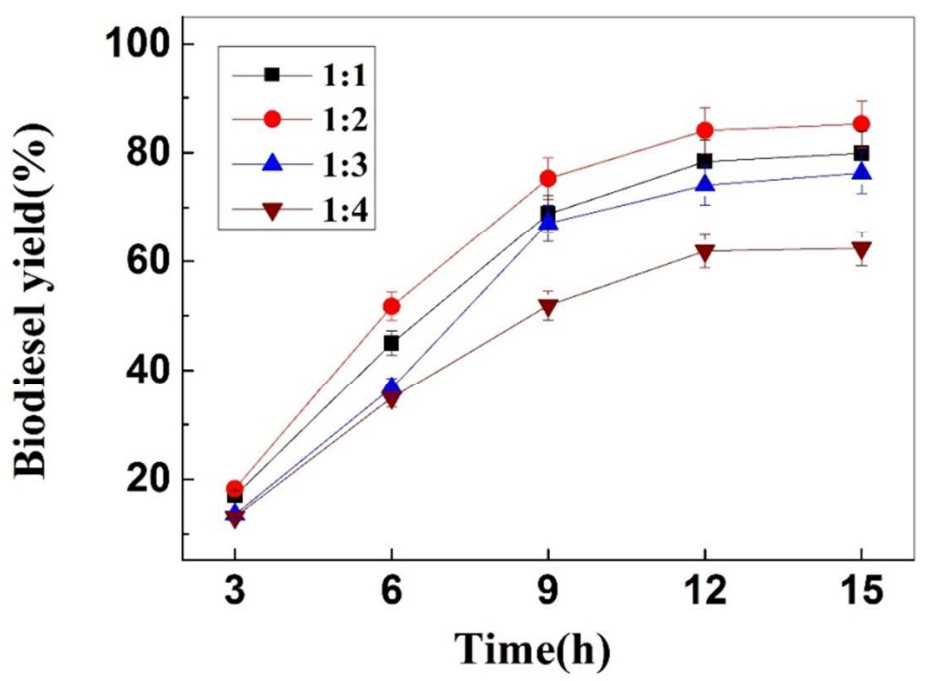

Figure S2 Effect of the molar ratio of oil $/ n$-hexane on biodiesel yield (The reaction conditions: Jatropha curcas L. oil $500 \mathrm{mg}$, molar ratio of ethanol to oil $5: 1,20 \%$ of IM-CLPCMC dosage to oil content, $30^{\circ} \mathrm{C}$ ) 


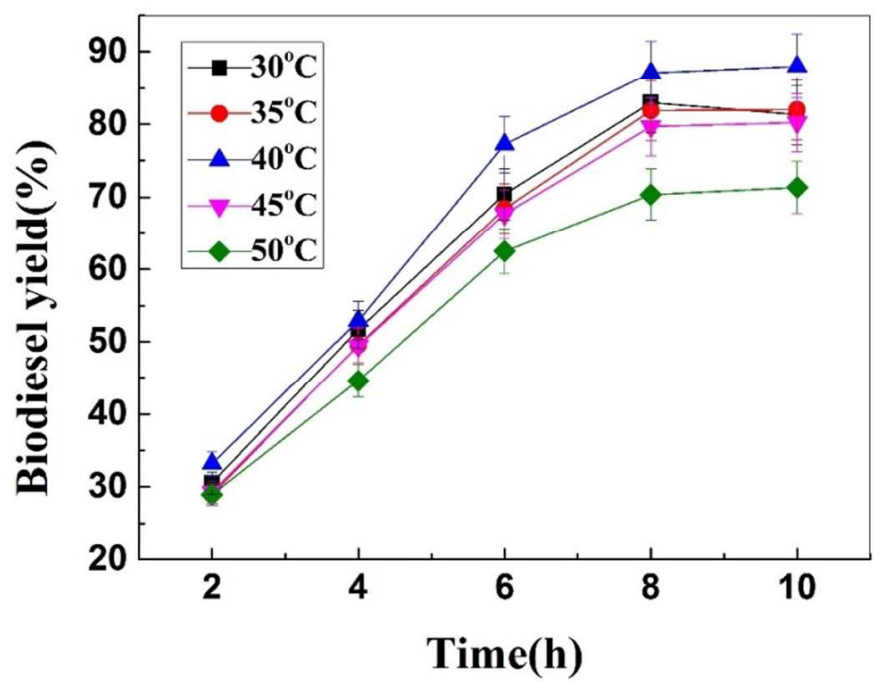

Figure S3 Effect of temperature on the yield of biodiesel (The reaction conditions:

Jatropha curcas L. oil $500 \mathrm{mg}$, molar ratio of ethanol to oil 5:1, 20\% of IM-CLPCMC dosage to oil content, molar ratio of oil to $n$-hexane 1:2) 


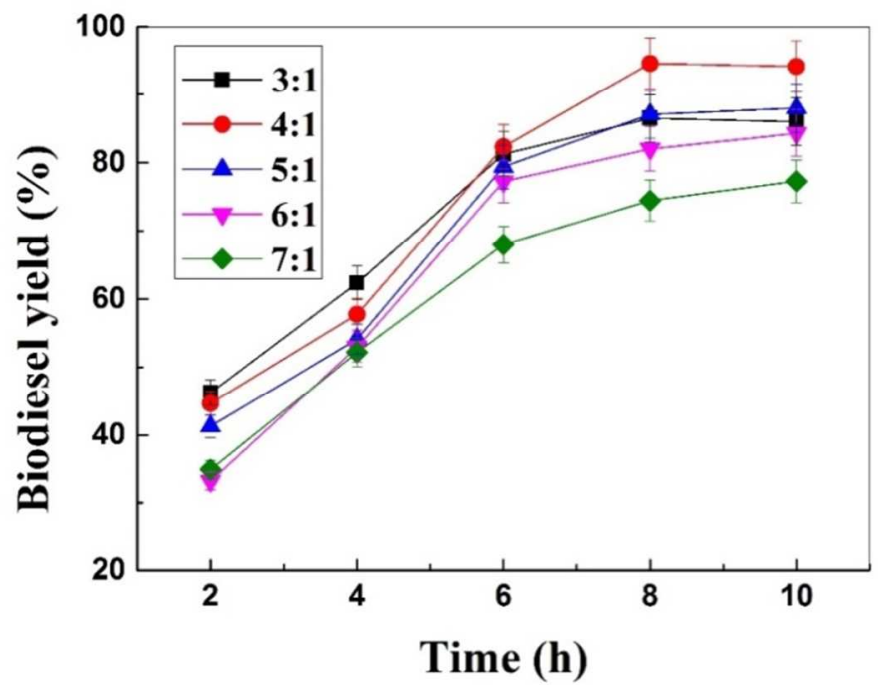

Figure S4 Effect of ethanol/oil molar ratio on the yield of biodiesel (The reaction conditions: Jatropha curcas L. oil $500 \mathrm{mg}, 20 \%$ of IM-CLPCMC dosage to oil content, molar ratio of oil to $n$-hexane $1: 2,40{ }^{\circ} \mathrm{C}$ ) 


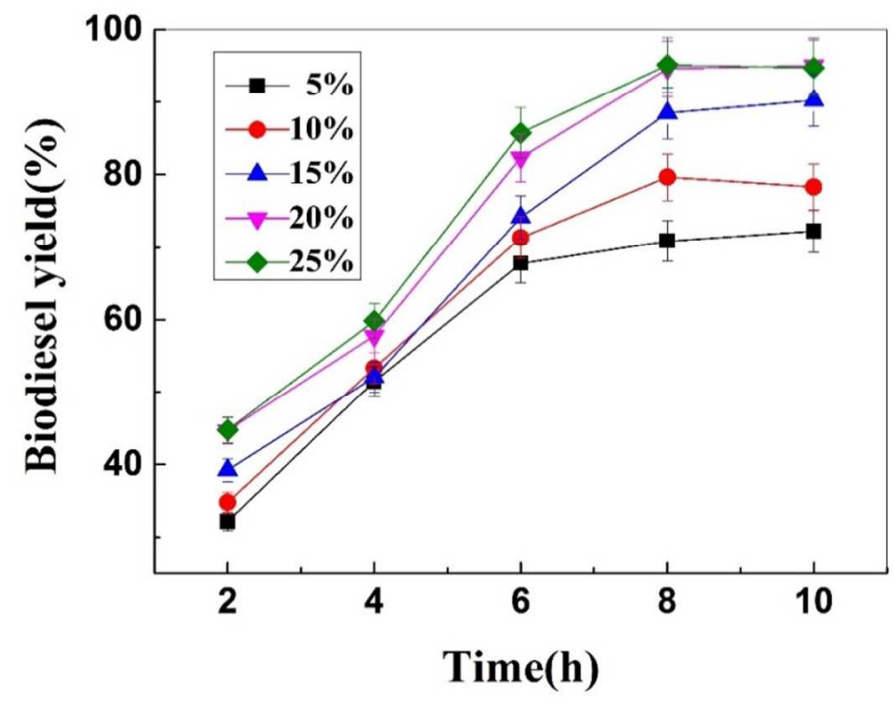

Figure S5 Effect of the dosage of IM-CLPCMC on yield of biodiesel (The reaction conditions: Jatropha curcas L. oil $500 \mathrm{mg}$, molar ratio of ethanol to oil 4:1, molar ratio of oil to $n$-hexane $1: 2,40{ }^{\circ} \mathrm{C}$ ) 